\title{
How Different Is the Cognition towards Dissertation between Candidates for Mathematics Master Degree and Reviewers?
}

\author{
Zezhong Yang1, Haiyin Zhou ${ }^{2}$ \\ ${ }^{1}$ The School of Mathematics, Shandong Normal University, Jinan, China \\ ${ }^{2}$ The Educational College, Shandong Normal University, Jinan, China \\ Email: zhongzee@163.com
}

Received 26 October 2015; accepted 13 November 2015; published 16 November 2015

Copyright (C) 2015 by authors and Scientific Research Publishing Inc.

This work is licensed under the Creative Commons Attribution International License (CC BY). http://creativecommons.org/licenses/by/4.0/

c) (i) Open Access

\begin{abstract}
This research focused on the cognition differences of candidates for Ed. $M$. in mathematics and reviewers towards dissertation. We showed 3 different levels dissertations to 37 candidates and 5 reviewers and analyzed the scores mean on 55 items. The results indicated that most candidates' cognitions towards dissertation were quite different from reviewers', especially the cognitions on dissertation literature review, question expressing and analysis, research methods, research works, application of professional knowledge, results and conclusion. These candidates' cognitions were overall superficial and not in place; even some of them were inexact or false. So the supervisors should introduce candidates for Ed. $M$. in mathematics some fundamental, concrete and detailed knowledge about dissertation in order to help them write out a good dissertation.
\end{abstract}

\section{Keywords}

\section{Ed. M. in Mathematics, Cognition Difference, Candidates, Dissertation}

\section{Introduction}

The dissertations' quality of candidates for Ed. M. in mathematics was overall not high these years in Mainland China [1]. What is the reason? Some researchers thought that the main reason was the unreasonable arrangement of supervisors and lack of standard [2]. Some researchers claimed that it was the insufficient learning and practicing about research method [3]. Some researchers argued that the imperfect cultivation system was the substantive reason [4]. Our preliminary research indicated the superficialness and deviation of cognitions should be the significant reason [5]. Then how big is the deviation? How different is the candidates' cognition from the re- 
viewers'? To answer these questions, we conducted a further investigation. We showed 3 different levels dissertations to candidates and reviewers, and asked them to asses and rate it. Our aim is to find out the differences between candidates and reviewers in assessment, and then to ascertain the candidates' concrete deficiency in their cognition towards dissertation and try to find some strategies to help candidates.

\section{Methodology}

\subsection{Instrument}

We chose 3 dissertations of Ed. M. in mathematics randomly published by Shandong normal university last year and respectively scored A, B and C by reviewers as object to be rated. The rating sheet was made through synthesizing present prevalent assessment sheets in Mainland China and reorganizing or rearranging their items, and had 55 items totally. The highest score of each item was 5 , and the lowest score was 0 . We intend to provide candidates and reviewers an unambiguous and detailed and comprehensive rating sheet so that they can rate accurately and expediently.

\subsection{Participants}

We recruited 37 candidates for Ed. M. in mathematics randomly from Shandong normal university, Qufu Normal University, Ludong University, Qingdao University and Liaocheng University. They all were freshmen of postgraduates majoring mathematics education, including 26 female candidates and 11 male candidates. Meanwhile, we recruited 5 reviewers who had assessed and rated candidates' dissertation over 5 years from above universities. Dissertations' copies and rating sheets were delivered to them by post. We asked them to post sheets back in a month.

\subsection{Data Collection}

We recalled 42 rating sheets totally at last, there into, 37 sheets were from candidates and 5 sheets were from reviewers. After rejecting 3 incomplete sheets from candidates' sheets, 39 effective rating sheets were available finally.

\subsection{Data Analysis}

We analyzed all responses by examining the scores mean of every item. To make conclusion, we examined all data in numerical, graphical and tabular forms, while considering the relevant research literature.

\section{Results}

\subsection{Descriptive Statistics}

The scores mean of each item related to dissertation is shown in Table 1. From Table 1 we knew that most scores which candidates rated towards A level dissertation were bigger than 4, while the scores which reviewers rated most were between 3 and 4 . Most scores which candidates rated towards B level dissertation were between 3 and 4, while the scores which reviewers rated mostly were between 2 and 3. Most scores which candidates rated towards $C$ level dissertation were between 3 and 4, while the scores which reviewers rated mostly were between 1 and 2 . So generally most scores rated by candidates were bigger than scores rated by reviewers.

\subsection{The Biggest Difference of Scores towards 3 Dissertations}

Figure 1 displayed the 55 items' mean difference between candidates' scores and reviewers' scores towards 3 dissertations. From Figure 1 we knew the almost each items' mean difference was getting bigger from A level dissertation to $C$ level dissertation. Some mean differences about $C$ level dissertation were over 3 , even 4 , such as the item 10,13, 14, 15, 17, 36, etc. Only a few items' mean differences were not obvious, such as item 43, 52, 53 and 54. So the candidates' cognitions about $\mathrm{C}$ level dissertation in general should be quite different from the reviewers'.

\subsection{The Most Controversial Items}

Figure 2 displayed the mean difference of all scores between candidates rated and reviewers rated towards each 
Table 1. Descriptive statistics of respondents.

\begin{tabular}{|c|c|c|c|c|c|c|}
\hline \multirow[t]{2}{*}{ Items } & \multicolumn{2}{|c|}{ A level dissertation } & \multicolumn{2}{|c|}{ B level dissertation } & \multicolumn{2}{|c|}{ C level dissertation } \\
\hline & Candidates & Reviewers & Candidates & Reviewers & Candidates & Reviewers \\
\hline 1. Does the question have theoretical value? & 3.91 & 3.6 & 3.52 & 3 & 3.76 & 2.2 \\
\hline 2. Does the question have practical value? & 4.31 & 4.6 & 4.08 & 3.8 & 4.94 & 3 \\
\hline 3. Is it novel? & 4.47 & 3.8 & 4.18 & 1 & 3.96 & 2.2 \\
\hline 4. Is the question suitable for Ed. M. candidates to research? & 4.07 & 3 & 3.82 & 3.8 & 4.22 & 3 \\
\hline 5. Did the author introduce the background of question clearly? & 4.26 & 3.8 & 4.11 & 2.2 & 3.82 & 3 \\
\hline 6. Is the literature review comprehensive? & 4.28 & 4.2 & 4.61 & 0.2 & 3.14 & 2.2 \\
\hline 7. Does the literature review include the last research results? & 4.33 & 3.6 & 3.98 & 0.2 & 3.45 & 1 \\
\hline 8. Did the author analyze previous researches? & 4.34 & 4.4 & 3.28 & 0.2 & 3.16 & 1 \\
\hline 9. Did the author summarize all previous results? & 4.95 & 4.6 & 3.77 & 0.2 & 3.67 & 1 \\
\hline 10. Did the author put forward a new question? & 3.94 & 3.8 & 3.06 & 0.2 & 4.56 & 1 \\
\hline 11. Is the introduction of question clear? & 3.73 & 3.8 & 4.43 & 3 & 4.23 & 1 \\
\hline $\begin{array}{l}\text { 12. Did the introduction of question include the source } \\
\text { of question? }\end{array}$ & 4.02 & 4.6 & 3.76 & 3 & 3.56 & 1 \\
\hline $\begin{array}{l}\text { 13. Did the introduction of question include details } \\
\text { on the significance of the research? }\end{array}$ & 4.94 & 4.6 & 3.89 & 3 & 4.28 & 1 \\
\hline 14. Is the introduction of methods clear? & 4.96 & 2.2 & 4.59 & 1 & 4.53 & 0.2 \\
\hline 15. Is the introduction of methods exact? & 4.03 & 3 & 4.56 & 1 & 4.33 & 0.2 \\
\hline 16. Is the selected method suitable for research? & 4.42 & 3.8 & 4.33 & 2.2 & 3.98 & 0.2 \\
\hline $\begin{array}{l}\text { 17. Did the author explain why these methods were } \\
\text { chosen adequately? }\end{array}$ & 4.34 & 2.2 & 4.63 & 0.2 & 4.54 & 1 \\
\hline 18. Are the definitions of relevant concepts clear? & 4.97 & 4.6 & 3.61 & 3.8 & 3.52 & 3 \\
\hline 19. Is the analysis of questions comprehensive? & 4.98 & 3.8 & 3.84 & 3 & 3.85 & 2.2 \\
\hline 20. Is the analysis of questions in-depth? & 4.67 & 3.8 & 4.85 & 2.2 & 4.59 & 2.2 \\
\hline 21. Is the analysis of questions logical? & 4.38 & 3.8 & 3.84 & 2.2 & 4.01 & 1 \\
\hline 22. Are all results clear? & 4.13 & 3.8 & 3.37 & 3 & 3.72 & 2.2 \\
\hline 23. Are all results rational? & 4.02 & 3.8 & 2.93 & 3 & 3.72 & 1 \\
\hline 24. Is the result enough? & 4.37 & 3 & 2.84 & 3 & 3.38 & 1 \\
\hline 25. Are results novel? & 4.51 & 3 & 2.43 & 1 & 3.89 & 1 \\
\hline 26. Are results believable? & 3.67 & 3.8 & 3.48 & 3 & 4.43 & 1 \\
\hline 27. Is the conclusion clear? & 4.43 & 3.8 & 3.53 & 3 & 4.28 & 1 \\
\hline 28. Is the conclusion reasonable? & 4.96 & 3 & 3.87 & 2.2 & 3.43 & 1 \\
\hline 29. Did the conclusion have full exposition? & 4.97 & 3 & 3.27 & 3 & 3.41 & 1 \\
\hline 30. Is the explanation of conclusion logical? & 4.51 & 3 & 3.02 & 2.2 & 3.35 & 1 \\
\hline 31. Is the conclusion new? & 4.61 & 2.2 & 1.84 & 1 & 2.86 & 1 \\
\hline 32. Did the conclusion answer previous question? & 4.67 & 3.8 & 2.85 & 1 & 3.94 & 1 \\
\hline 33. Is the conclusion valuable? & 3.85 & 4.6 & 3.47 & 2.2 & 3.81 & 1 \\
\hline 34. Did the author apply their professional knowledge? & 4.38 & 4.6 & 3.87 & 3 & 4.44 & 1 \\
\hline 35. Is the application of professional knowledge proper? & 4.59 & 3.8 & 4.91 & 3 & 4.08 & 2.2 \\
\hline 36. Is the professional knowledge which was used rich? & 4.66 & 3.8 & 4.83 & 2.2 & 4.68 & 1 \\
\hline 37. Is the research work comprehensive? & 3.47 & 3 & 3.24 & 2.2 & 4.67 & 1 \\
\hline 38. Is the research work enough? & 4.27 & 3 & 3.67 & 2.2 & 4.07 & 1 \\
\hline 39. Is the research work believable? & 4.05 & 3.8 & 2.81 & 3 & 4.14 & 1 \\
\hline $\begin{array}{l}\text { 40. Are all methods used in research works mentioned } \\
\text { in the previous part of method? }\end{array}$ & 4.98 & 3 & 2.87 & 3 & 2.92 & 1 \\
\hline 41. Is the using of methods reasonable? & 3.89 & 3 & 3.82 & 3 & 3.94 & 1 \\
\hline 42. Is there innovation in research methods? & 1.35 & 1 & 2.8 & 0.2 & 3.54 & 1 \\
\hline 43. Is the arrangement clear? & 4.95 & 3.8 & 4.44 & 3 & 3.28 & 3 \\
\hline 44. Is the arrangement reasonable? & 4.09 & 3.8 & 4.61 & 3 & 3.24 & 2.2 \\
\hline 45. Is the arrangement of chapter logical? & 4.35 & 3.8 & 3.34 & 3.8 & 3.97 & 1 \\
\hline 46. Is the language fluent? & 3.75 & 3.8 & 4.35 & 3.8 & 4.44 & 3 \\
\hline 47. Are the tables and figures clear? & 3.41 & 3.8 & 4.49 & 3.8 & 4.46 & 2.2 \\
\hline 48. Are the tables and figures right? & 3.81 & 3.8 & 3.86 & 3.8 & 4.15 & 3 \\
\hline 49. Are the symbols and formula clear? & 3.89 & 3.8 & 3.66 & 3.8 & 3.95 & 2.2 \\
\hline 50. Are the symbols and formula right? & 4.32 & 3.8 & 3.98 & 3.8 & 4.26 & 3 \\
\hline 51. Are the title directory, abstract and key words standard? & 3.71 & 4.6 & 4.31 & 4.6 & 3.97 & 3 \\
\hline 52. Is its printing standard? & 2.42 & 4.6 & 2.58 & 4.6 & 4.96 & 4.6 \\
\hline 53. How is its binding? & 4.96 & 4.6 & 3.52 & 4.6 & 4.49 & 4.6 \\
\hline 54. Is the reference standard? & 4.71 & 4.6 & 4.36 & 4.6 & 3.73 & 3 \\
\hline 55. Is its appendix standard? & 2.32 & 4.6 & 4.47 & 4.6 & 3.76 & 0.2 \\
\hline SUM & 231.33 & 202.8 & 206.43 & 140.6 & 217.46 & 91 \\
\hline MEAN & 4.206 & 3.6873 & 3.7533 & 2.5564 & 3.9538 & 1.6545 \\
\hline
\end{tabular}




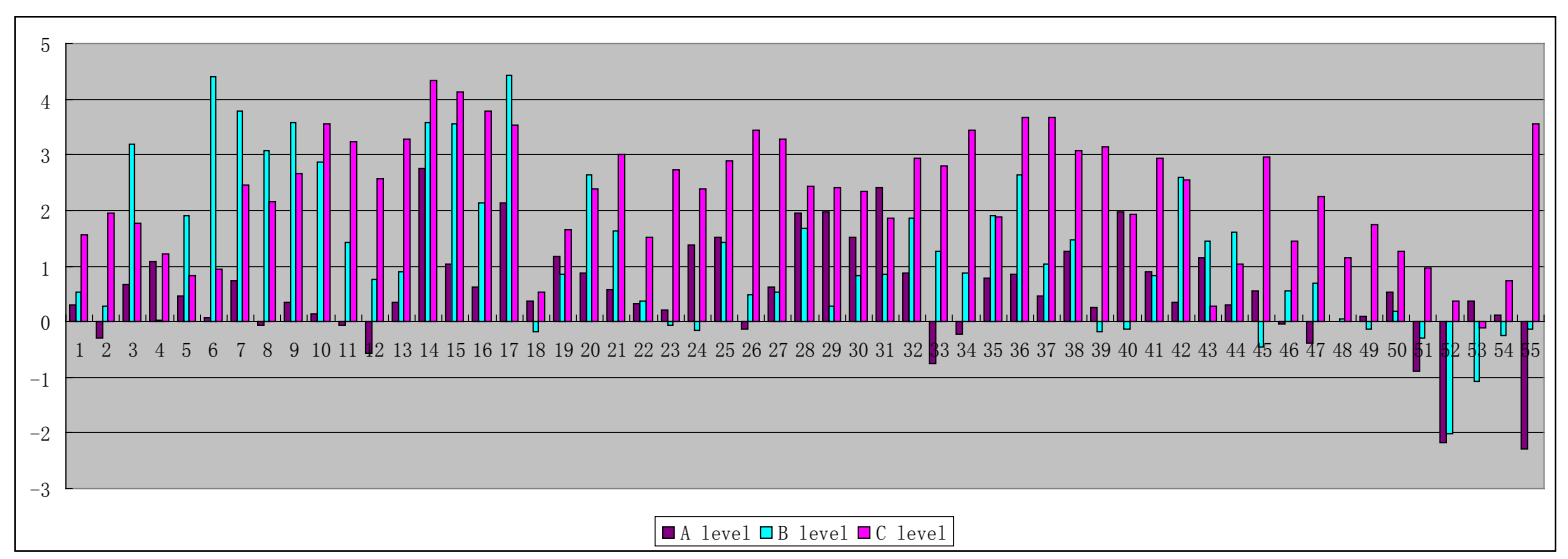

Figure 1. The mean differences towards 3 dissertations.

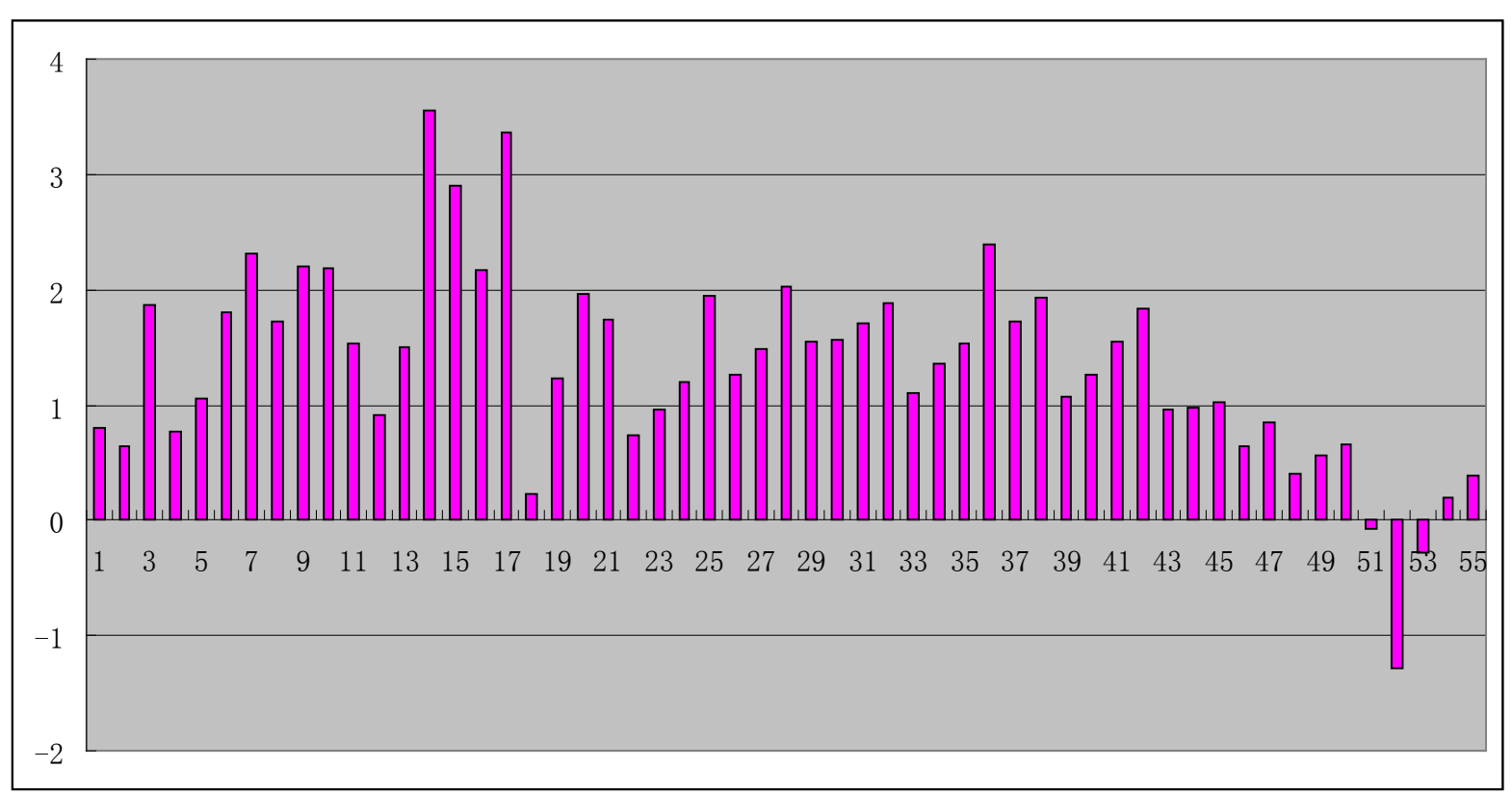

Figure 2. The mean difference of all scores towards each item.

item in all 3 dissertations. From Figure 2 we knew that the most controversial items were: 7. Does the literature review include the last research results? 9. Did the author summarize all previous results? 10. Did the author put forward a new question? 14. Is the introduction of methods clear? 15. Is the introduction of methods exact? 16. Is the selected method suitable for research? 17. Did the author explain why these methods were chosen adequately? 20. Is the analysis of questions in-depth? 25. Are results novel? 28. Is the conclusion reasonable? 32. Did the conclusion answer previous question? 36. Is the professional knowledge which was used rich? 38. Is the research work enough? 42. Is there innovation in research methods?

\section{Discussion}

Based on the results above, the 55 items' scores that candidates rated towards 3 dissertations were usually bigger than reviewers rated and changed not much from A level dissertation to C level dissertation. It seemed that in present candidates' opinion all passed and published dissertations were good. This indicated there were many differences in cognition of dissertations between present candidates and reviewers in detail. Most candidates' concrete cognitions towards dissertation were obviously superficial and not in place, even some of them were inexact, otherwise they could judge subtle differences of different level dissertations accurately. 
The number of most controversial items was 14 totally. The scores that candidates rated for these 14 items were generally much bigger than reviewers rated. This phenomenon indicated the biggest cognition differences towards dissertations between present candidates and reviewers were mainly in literature review, question, research methods, research works, professional knowledge, results and conclusion. It seemed most present candidates did not completely understand what the literature review and what research method was, and did not realize the literature review must include the latest researches results, summarize all previous results and put forward some new questions at last yet. It seemed that they did not know what the clear and exact introduction about research method was, what suitable method for a research and what the innovation of research method was, they did not know why the research methods must be explained adequately and how to do it. It seemed that they do not know what the comprehensive or deep analysis to questions was, and did not know how to judge research results were novel or not and the conclusion' coming was reasonable or not. Concerning the research works, it seemed that the candidates could not judge whether the research work was enough or not, even they did not know what the enough research was. Since if they knew the all above very well and exactly, the scores differences were affirmatively not so big.

\section{Conclusion}

Even though the number of dissertations selected for rating only is 3, and participants are not so many, the results we obtained are unquestionably significant and reliable. Based on the results above, we knew that the most cognitions of candidates towards dissertation were quite different from those of reviewers, especially the cognition on literature review, question expressing and analysis, research methods, research works, application of professional knowledge, results and conclusion. These candidates' cognitions were superficial and not in place; even some of them were inexact. In their views, all passed and published dissertations were good. So it is necessary for supervisors to let candidates know the fundamental knowledge related to above aspects well in the process of guiding candidates for Ed. M. in mathematics to write their dissertations. The supervisors must teach candidates some concrete and detailed criteria of dissertation. The supervisors should guide candidates to know what the clear and exact introduction of method is, what the comprehensive analysis towards questions is, what the novel results are, what reasonable conclusion coming is and what the method innovation is, etc. And what's more, the supervisors should let candidates know how to do some of them, such as how to introduce the question and method clearly and exactly, how to analyze the question comprehensively and how to obtain a conclusion reasonably, etc. Because only knowing more and doing much can change and improve people's cognition, especially for current candidates for Ed. M. in mathematics, even more so. The candidates only have known more knowledge especially relevant detailed criteria about dissertation and known how to do the research works, so that their cognitions about dissertation can be improved, and furthermore they can write out a good dissertation.

\section{Funding}

Supported by the project of research on enhancing quality of full-time master of mathematics education candidate's dissertation (SDYC14048).

\section{References}

[1] Hou, Zh.T. (2010) Research on Quality Assurance of Master of Education Dissertation: Reviews and Reflection. Academic Degrees \& Graduate Education, 6, 40-44.

[2] Yang, Q.L. (2005) The Problems and Its Explanation Appeared in Practice of Master Education. Research in Educational Development, 6, 77-80.

[3] Li, G.F. and Yang, Z.P. (2011) The Problems, Reasons and Countermeasures of Master of Education Dissertations. Academic Degrees \& Graduate Education, 2, 20-25.

[4] Zhang, D.Q. (2011) Mathematics Education for the Master Degree Thesis Writing Analysis of the Investigation. Journal of Mathematics Education, 6, 25-29.

[5] Yang, Z.Z. and Sun, D.D. (2015) Research on Full-Time Master of Mathematics Education Candidates' Cognition of Dissertation. Open Journal of Social Sciences, 3, 46-50. http://dx.doi.org/10.4236/jss.2015.310007 